\title{
Enhancing Safe Medication Use for Pediatric Patients in the Emergency Department
}

\author{
Julie Greenall, Pauline Santora, Christine Koczmara, and Sylvia Hyland
}

Contributions to this column are prepared by the Institute for Safe Medication Practices Canada (ISMP Canada), a key partner in the Canadian Medication Incident and Prevention System, and may include, with permission, material from the ISMP Canada Safety Bulletin. The present article is based on "Hydromorphone intended for an adult patient inadvertently administered to an infant", ISMP Canada Saf Bull 2008;8(6):1-3. From time to time, ISMP Canada invites others to share learning based on local initiatives.

\section{INTRODUCTION}

$\mathrm{A}^{\mathrm{s}}$ Canadian study assessing the incidence of medication errors in a pediatric emergency department found prescribing errors in $10.1 \%$ of charts reviewed and administration errors in $3.9 \% .{ }^{1}$ The authors cited earlier work by others indicating that preventable errors are significantly more common in the emergency department than in other hospital departments. ${ }^{2,3}$ This heightened risk in the emergency department is thought to result from the need for medications to be given urgently, which means that many drugs are kept in ward stock. In addition, there is generally no pharmacist review of medication orders originating in the emergency department; patients seen in the emergency department may have only a brief, focused encounter with the physician and nurse before medications are ordered and given; a complete medical and drug history may not be available; physicians and nurses are often caring for several patients at the same time in an environment where interruptions are common; and use of high-alert drugs is common. ${ }^{1,4,5}$ The authors suggested that of the approximately 50000 children seen annually in their emergency department, 5000 may be subjected to a medication error, and half of these errors might be clinically significant. Adding to these identified risks for emergency departments in pediatric specialty hospitals is the fact that many Canadian hospitals provide care to pediatric patients alongside adults in the emergency department, which greatly increases the risk of harm associated with an "incorrect patient" error. This risk of harm is compounded when a high-alert medication is involved, as is illustrated by the following case, in which an infant inadvertent- ly received a dose of hydromorphone intended for an adult patient. This incident was highlighted in a recent ISMP Canada Safety Bulletin. ${ }^{6}$ The current article describes findings from an analysis of the incident and suggests opportunities for pharmacist intervention in the emergency department to reduce the likelihood of medication errors.

\section{CASE REPORT}

A mother brought her 9-month-old infant to the emergency department of a community hospital with fever and symptoms of ear pain. Around the same time, an adult patient who was receiving palliative care, whose surname was similar to that of the infant, presented to the emergency department with uncontrolled pain. She was a patient of the attending physician on duty, who was also a family practitioner in the community. After examining the adult patient, the physician inadvertently picked up the infant's chart and wrote an order for hydromorphone (Dilaudid) $4 \mathrm{mg}$ to be given orally.

Shortly afterward, the infant's nurse picked up the chart and reviewed the order. She immediately conferred with another nurse about the appropriateness of the order for an infant. She then approached the physician to ask if he had intended to order the hydromorphone $4 \mathrm{mg}$. The physician verbally confirmed the order as written.

The nurse retrieved the hydromorphone from the automated dispensing cabinet and performed a double check of the drug and dose with another nurse. She verified the infant's identification, age, and allergies with the mother before 
administering the hydromorphone. In response to questioning from the mother, the nurse explained that the medication was "for pain". After administering the hydromorphone, the nurse asked the mother what other instructions the physician had given her, at which point the mother indicated that her child had not yet been examined by a doctor.

The nurse realized that an error had probably occurred and immediately informed the physician, who disclosed the error to the mother. Immediate remedial steps were taken, including administration of activated charcoal via a nasogastric tube and administration of intravenous naloxone. The infant was transferred to a regional pediatric referral centre and was discharged the following day.

\section{CONTRIBUTING FACTORS}

The facility undertook a root cause analysis of the incident and identified the following possible contributing factors:

- The fact that the adult palliative care patient was known to the physician led the physician to deviate from the usual practice of taking the chart to the bedside and verifying the patient's identification before writing the medication order. In addition, the physician wrote the medication order without an accompanying medical assessment note.

- When the nurse requested confirmation of the order from the physician, neither explicitly identified the patient. As a result, both parties assumed that the communication had been about the same patient.

- The 2 patients had similar surnames.

- Recent transition to the use of an automated dispensing cabinet in the emergency department for both ward stock and night cupboard stock led to ready accessibility of the hydromorphone. (Previously, hydromorphone had not been stocked in the emergency department and the nursing staff had to obtain it through the pharmacy.)

- Nursing staff in the emergency department lacked familiarity with, and understanding of, the potency of hydromorphone, a drug that the emergency department staff did not routinely use and had not previously been able to access without the involvement of pharmacy staff.

- Neither published drug information references nor a pharmacist was consulted to determine the appropriateness of administering hydromorphone to an infant and the appropriateness of the dose.

- $\quad$ Both pediatric and adult ward stock were available together in the patient care area, and children and adults were being treated in the same location, without specified differentiation of processes.

\section{ANALYSIS AND RECOMMENDATIONS}

The root cause analysis conducted by the hospital identified several themes, all of which present opportunities to enhance safety, including availability of medications, communication, education, and the care processes for pediatric and adult patients.

The following selected recommendations are relevant to pharmacists:

- Use 2 identifiers (e.g., patient name, date of birth, hospital identification number) at every stage of the medicationuse process.

- Ensure that all communication about any patient includes patient identifiers. Use of the "SBAR process", as described in the ISMP Canada Safety Bulletin, ${ }^{6}$ is one way of doing this.

- $\quad$ Require that all medications ordered for pediatric patients include the calculated dose (e.g., dose per kilogram), in accordance with facility-approved pediatric references, and include review of this information as part of the verification process to ensure appropriateness of the dose.

- Ensure that pertinent and up-to-date pediatric drug information is readily available.

- Ensure that there is a process in place to provide access to a pharmacist for drug information.

- If hydromorphone must be stocked in the emergency department because of the particular population served (e.g., palliative care patients), ensure that access is restricted. Include an independent double-check and an on-screen alert for automated dispensing cabinets; e.g., "Hydromorphone (Dilaudid) is a highly potent opioid. Do you still want to proceed?"

Additional details and recommendations can be found in the full report of this case, published in the ISMP Canada Safety Bulletin. ${ }^{6}$

\section{DISCUSSION}

The importance of reviewing external reports of errors, such as this one, to assess the potential for local occurrence cannot be overemphasized. ${ }^{7,8}$ Such reviews provide pharmacists with an opportunity to enhance their leadership role in advocating for safe medication practices within their organizations. Selbst and others ${ }^{9}$ identified pharmacist involvement in the emergency department as a strategy for preventing medical errors in pediatric emergency medicine, based on success in inpatient care. Idrees and Clements" noted that "Pharmacists are established members of multidisciplinary teams throughout other areas of the hospital. . . . However the emergency department has been an area that is largely neglected."

"Incorrect patient" errors represent only one of the types of medication error that can occur in the emergency department. Some additional practical ways in which pharmacists can help to enhance medication safety for pediatric patients in the emergency department include the following: 
- Ensure that approved references are readily available in areas where they may be needed, such as in all medication rooms and on cardiac arrest carts. The same references should be available in the pharmacy.

- Encourage all care team members to routinely verify doses for pediatric patients, rather than relying on memory.

- Ensure that calculators are readily accessible in all areas where care team members may need to perform dose calculations.

- Identify medications commonly used for pediatric patients (oral and parenteral) and provide dosage charts for quick reference.

- $\quad$ Routinely assess medication storage areas in the emergency department, including cardiac arrest carts, to identify improvement opportunities. ${ }^{9}$ One example is availability of "ready-to-use" dosage forms appropriate for pediatric use, ${ }^{10}$ beginning with high-alert medications and those that may be required in an emergency.

- Provide educational support to nursing staff through in-services on new medications and medications that are most likely to cause harm if an error occurs (e.g., high-alert drugs such as hydromorphone and insulin).

- Provide order screening for new medication orders, particularly for high-alert drugs.

Ideally, these activities would be conducted by a dedicated emergency department pharmacist. The level of pharmacist involvement in emergency departments in Canadian hospitals is highly variable, however, and service may be limited to one shift or a portion of a shift per day, with limited availability on weekends. Of 126 institutions that responded to the 2007/2008 survey of hospital pharmacy in Canada, ${ }^{11} 77$ (61\%) indicated that pharmacists were assigned to the emergency department. Among respondents, teaching hospitals were more likely to provide this service than nonteaching hospitals $(72 \%$ vs $58 \%$ ). The actual number of Canadian emergency departments with dedicated pharmacists is not known, but given US data, it is likely to be substantially lower than this report would suggest. New US survey results of facilities offering emergency medicine residency programs found that $8 \%$ of institutions had a dedicated pharmacist in the emergency department $24 \mathrm{~h} /$ day, $22 \%$ had partial coverage, and $77 \%$ had no pharmacist coverage. $^{12}$ Two previous US studies found dedicated pharmacists in $3.5 \%^{13}$ and $14 \%^{14}$ of hospital emergency departments. In those hospitals where pharmacists are available in the emergency department, orders for pediatric patients, particularly orders for identified high-alert medications, can be given priority for review by the pharmacist before administration. In hospitals without a dedicated emergency department pharmacist, there is opportunity to consider additional supports that can be provided within available resources, as well as opportunities for future implementation.
A key patient safety principle is the need to assess the potential for harm related to the particular populations served by a health care organization; pediatric patients clearly represent a vulnerable patient group requiring special attention. Emergency departments, with high patient turnover and diverse and unpredictable patient needs, have greater medication safety challenges than do inpatient units, and these challenges are magnified for pediatric patients. In a guideline for preventing medication errors in pediatrics, Levine and others ${ }^{15}$ stated that "Because of their specialized knowledge of medications and their role in the drug distribution process, pharmacists are in a unique position to prevent medication errors and ensure appropriate medication use". These authors also identified a key role for pharmacists in preventing medication errors in pediatrics as simply "be[ing] available regularly in patient-care areas to serve as a source of information" ${ }^{15}$ It is hoped that this overview of a medication-related incident involving a young child and the recommendations that have been suggested for consideration will encourage individual pharmacists in hospital settings to take action to review the management of pediatric patients in their own emergency departments and to identify ways in which they can provide assistance to enhance safe medication practices in this specialty area of the hospital.

\section{References}

1. Kozer E, Scolnik D, Macpherson A, Keays T, Shi K, Luk T, et al. Variables associated with medication errors in pediatric emergency medicine. Pediatrics 2002;110(4):737-742.

2. Leape LL, Brennan TA, Laird N, Lawthers AG, Localio AR, Barnes BA, et al. The nature of adverse events in hospitalized patients. Results of the Harvard Medical Practice Study II. N Engl J Med 1991;324(6):377-384.

3. Thomas EJ, Studdert DM, Burstin HR, Orav EJ, Zeena T, Williams EJ, et al. Incidence and types of adverse events and negligent care in Utah and Colorado. Med Care 2000;38(3):261-271.

4. Fairbanks RJ, Hays DP, Webster DF, Spillane LL. Clinical pharmacy services in an emergency department. Am J Health Syst Pharm 2004;61(9):934-937.

5. Idrees U, Clements E. The state of U.S. emergency care: a call to action for hospital pharmacists. Ann Pharmacother 2006;40(12):2251-2253.

6. Hydromorphone intended for an adult patient inadvertently administered to an infant. ISMP Can Saf Bull 2008[cited 2009 Jan 12];8(6): 1-3. Available from: http://www.ismp-canada.org/download/ ISMPCSB2008-06Hydromorphone.pdf

7. Using external errors to signal a clear and present danger. ISMP Med Saf Alert 2008[cited 2009 Jan 12];13(22). Available from: http:// www.ismp.org/newsletters/acutecare/articles/20081106.asp

8. Conway JB. Could it happen here? Learning from other organizations' safety errors. Healthc Exec 2008 Nov/Dec [cited 2009 Jan 12];:64-66. Available from: http:/www.ihi.org/NR/rdonlyres/ 0C5060BC-35D2451A-AC4F-922D2F1320C8/0/ConwayCouldItHappenHere ACHENov08.pdf

9. Selbst SM, Levine S, Mull C, Bradford K, Friedman M. Preventing medical errors in pediatric emergency medicine. Pediatr Emerg Care 2004;20(10):702-709.

10. Greenall J. Medication safety alerts: Cost and risk: a need for rebalancing. Can J Hosp Pharm 2006;59(2):81-82. 
11. Bussières JF. Clinical pharmacy services. In: Babich M, Hall KW, Johnson N, MacGregor P, Roberts N, Bussières JF, et al., editors. Hospital pharmacy in Canada: $2007 / 2008$ report. Eli Lilly; 2009 [cited 2009 Mar 13]. p 8-24. Available from: http://www.lillyhospitalsurvey.ca/hpc2/content/2008_report/ clinpharmacyserv.pdf

12. Szczesiul JM, Fairbanks RL, Hildegrand JM, Hays DP, Shah MN. Survey of physicians regarding clinical pharmacy services in academic emergency departments. Am J Health Syst Pharm 2009;66(6):576-579.

13. Pedersen CA, Scheider PJ, Scheckelhoff DJ. ASHP national survey of pharmacy practice in hospital settings: dispensing and administration2005. Am J Health Syst Pharm 2006;63(4):327-345.

14. Thomasset KB, Faris R. Survey of pharmacy services provision in the emergency department. Am J Health Syst Pharm 2003;60(15): 1561-1564.

15. Levine SR, Cohen MR, Blanchard NR, Frederico F, Magelli M, Lomax $\mathrm{C}$, et al. Guidelines for preventing medication errors in pediatrics. J Pediatrr Pharmacol Ther 2001;6:426-442.

Julie Greenall, RPh, BScPhm, MHSc, FISMPC, is a Project Leader with the Institute for Safe Medication Practices Canada, Toronto, Ontario.

Pauline Santora, RPh, BScPhm, PharmD, is an Emergency Program Pharmacist who was previously with the William Osler Health Centre, Brampton, Ontario.
Christine Koczmara, RN, BSC, is a Senior Analyst with the Institute for Safe Medication Practices Canada, Toronto, Ontario.

Sylvia Hyland, RPh, BScPhm, MHSc, is Vice President and Chief Operating Officer of ISMP Canada, Toronto, Ontario.

ISMP Canada homepage: www.ismp-canada.org

e-mail: info@ismp-canada.org

Medication incidents (including near misses) can be reported to ISMP Canada in 1 of 2 ways:

- through the secure web portal at http://www.ismp-canada.org/ err_report.htm

- by telephone at 416.733 .3131 or toll-free at 1.866.544.7672 (1.866.54.ISMPC)

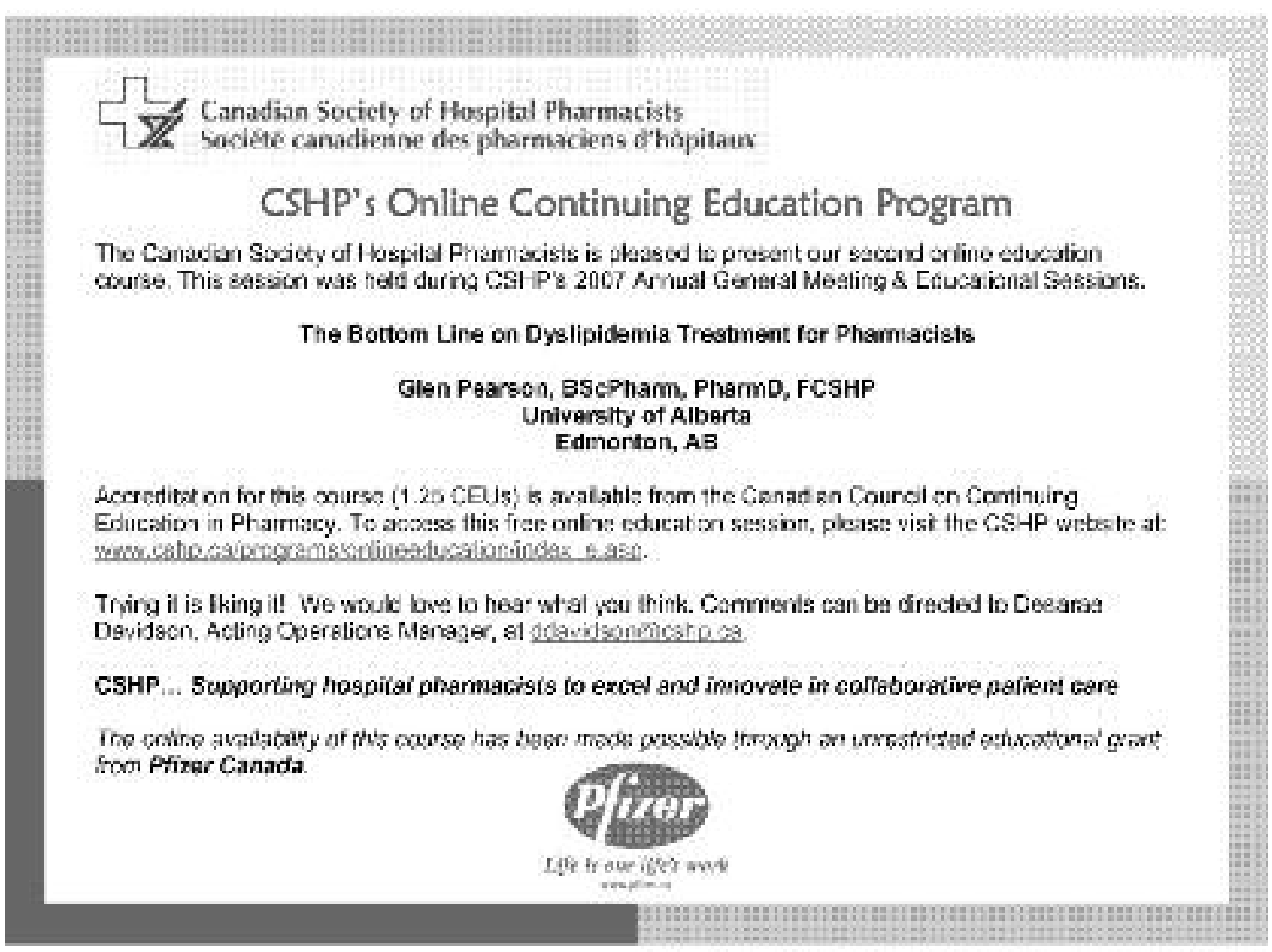

